\title{
Multi-cracking in brittle thin layers and coatings using a FFM model
}

\author{
Dominique Leguillon ${ }^{1 *}, \mathrm{Jia}^{2}{ }^{2}$, Eric Martin ${ }^{3}$
}

${ }^{1}$ Institut Jean le Rond d'Alembert, CNRS UMR 7190, Sorbonne Universités, UPMC Université Paris 06, F-75005 Paris, France.

${ }^{2}$ Laboratoire des Sciences des Procédés et des Matériaux, CNRS UPR 3407, Institut Galilée, Université Paris 13, F-93430 Villetaneuse, France.

3 Laboratoire des Composites Thermo-Structuraux, CNRS UMR 5801, Université de Bordeaux, F-33600, Pessac, France.

* Corresponding author: dominique.leguillon@upmc.fr

\begin{abstract}
Multi-cracking of brittle thin layers and coating is a phenomenon difficult to model especially because of the large number of cracks that may occur. It is overcome herein by conducting calculations, not on the whole structure, but only on a simplified cell that is representative of the structure by periodic duplication. The coupled criterion is applied within this representative cell (RC) and allows to predict the crack density under an increasing applied load, the length of the RC being a variable parameter of the model. Based on the simultaneous fulfilment of an energy and a stress conditions, it allows to take into account thin layers where the crack onset is energy driven and thicker layers where the stress condition governs the transverse cracking. Results are in a good agreement with various experiments found in the literature, conducted on cross-ply laminates and coated substrates.
\end{abstract}

\section{Introduction}

Multi-cracking is a complex phenomenon that takes place in brittle materials under some specific conditions of geometry (thin layers, coatings) and loading (residual stresses (Fu et al., 2013; Leguillon et al., 2016), thermal shocks (Bahr et al., 2010; Jiang et al., 2012), tension (Garrett and Bailey, 1977; Parvizi et al., 1978; Highsmith and Reifsnider, 1982; Laws and Dvorak, 1988; Huchette, 2005), bending (Beuth, 1992; Schulze and Erdogan, 1998; Kim and Nairn, 2000; Xia and Hutchinson, 2000).

We focus especially on the transverse cracking of inner layers in a cross-ply laminate or of thin coatings deposited on a substrate submitted to a mechanical loading. Note that the transverse cracking is not in itself a hazardous mechanism for the structure, except in some cases of metal/ceramic composites where it results in a significant loss of stiffness (Kashtalyan et al., 2016). But it can be responsible for other more harmful degradations like delamination and spalling. It is in a way a precursor of damage. For the purpose of our model, we assume that this mechanism develops into parallel cracks spaced more of less regularly and going through the whole thickness and width of the specimens, thus allowing the use of a 2D model. This does not seem unrealistic looking at the micrographs by Garrett and Bailey (1977) on transverse cracking in a cross ply laminate or by Ganne et al., (2002) on tungsten coatings.

Our goal is to establish a model to predict the crack density as a function of the increasing applied load. Indeed, there is not so many models in the literature even if a thorough search 
would probably disclose other related works. We have selected two of them to compare with our results: Laws and Dvorak (1988) for cross-ply laminates and Kim and Nairn (2000) for coatings. The present approach is based on the concept of Finite Fracture Mechanics (FFM) (Hashin, 1996): "The concern is with spontaneous appearance of many cracks. Spontaneous crack formation implies that new cracks appear in a very short time and it is not possible or of interest to follow the history of their development." However, Hashin $(1985,1996)$ as well as Nairn (Nairn et al., 1993) or Andersons et al. (2008) used a single energy condition for crack initiation that can reveal ineffective in some particular geometries as seen later on in Section 2.2 and 4.1. The coupled criterion proposed by Leguillon (2002) improved this concept, adding a stress condition and stating that both conditions must be fulfilled simultaneously. It allows removing the paradoxes that may arise from the use of a single energy criterion. It has been successfully applied by Garcia et al. (2014) to a detailed analysis of the onset and growth of a transverse crack in cross-ply laminates.

There remains an obstacle related to the high number of cracks that may arise during the multi-cracking mechanisms. This is solved by performing the analysis on a representative cell assumed to be reproduced periodically to describe the whole multi-cracked structure. This approach was first sketched to model lattices of cracks in functionalized coatings (Leguillon, 2014) and then improved in the analysis of the surface cracking pattern of an oxidized polymer (Leguillon, 2016) in bending. It is now applied to the transverse cracking in cross-ply laminates and coated substrates.

It should of course be recalled that the use of a representative cell with periodic boundary conditions, to take into account the effects of a microstructure, has been the subject of numerous works grouped under the name of periodic homogenization theory (SanchezPalencia, 1980). These works have rapidly been concerned with the behavior of composite materials, their damage and more recently with the rupture emanating from microscopic mechanisms of debonding (Belytschko et al., 2008; Gosh et al., 2007; Greco et al., 2014; Greco et al., 2015). In these periodic homogenization approaches, the choice of the representative cell is done once and for all and is guided by the micro-structure of the material. Whereas in the present analysis, there is no initial periodic microstructure, periodicity appears with the mechanism of transverse cracking and evolves together with it.

Figure 1 depicted schematically the two experiments we are interested in: (i) tensile test on a cross-ply $\left[0 \mathrm{x}, 90_{\mathrm{y}}\right]_{\mathrm{S}}$ laminate ( $\mathrm{x}$ and $\mathrm{y}$ are the number of plies used to form the layers and $\mathrm{S}$ means that this structure is repeated using a mirror symmetry) with transverse cracking of the inner ply (Parvizi et al., 1978; Laws and Dvorak, 1988; Huchette, 2005), (ii) bending test on a coating/substrate (C/S) system with transverse cracking of the coating (Kim and Nairn, 2000). Components are assumed to be linear elastic. In the choice of the examples, we have tried to avoid the presence of strong residual stresses, anyway they can be considered as a special case of loading (Leguillon et al., 2014). 

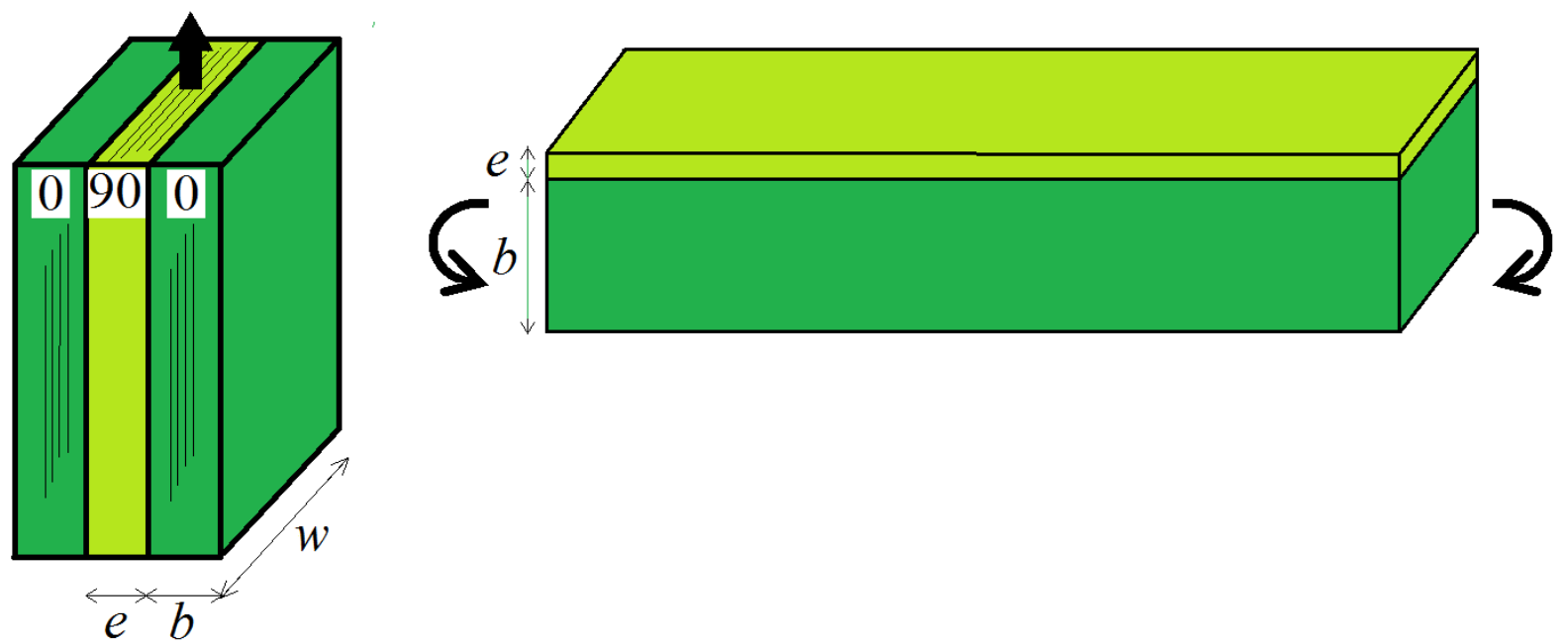

Figure 1. Schematic view of the experiments leading to multi-cracking that are analyzed herein: tensile test on a cross-ply laminate (left), bending test on a coating/substrate $(\mathrm{C} / \mathrm{S})$ system (right).

This paper is outlined as follows. Section 2 briefly recalls the bases of the coupled criterion and proposes a simple illustration of the origin of multi-cracking. In the next section, it is shown how this criterion can be used in a representative periodic cell, leading to the prediction of crack density under an increasing loading. Section 4 confirms that the theory works rather well by comparing the predictions to different experiments found in the literature. A conclusion follows.

\section{The coupled criterion (CC)}

\subsection{The coupled criterion}

The $\mathrm{CC}$ was presented many times in the literature, refer to the review paper by Weissgraeber et al. (2016) for a detailed description and an exhaustive list of references. It is briefly outlined below.

The CC is based on two conditions in energy and stress that must be fulfilled simultaneously. The first one, relying on an energy balance, expresses that fracture can occur if the change in potential energy $-\Delta \boldsymbol{W}^{\mathrm{P}}$ prior to and after the onset of a crack of length $l$ exceeds the energy consumed to create such a crack (written in 2D omitting the thickness of the specimen)

$$
-\Delta \boldsymbol{W}^{\mathrm{P}} \geq \mathcal{G}_{\mathrm{Ic}} l \Rightarrow \mathcal{G}^{\text {inc }}(l)=-\frac{\Delta \boldsymbol{W}^{\mathrm{P}}}{l} \geq \mathcal{G}_{\mathrm{Ic}}
$$

where $\mathcal{G}_{\text {Ic }}\left(\mathrm{MPa} \mathrm{mm}=10^{3} \mathrm{~J} \mathrm{~m}^{-2}\right)$ is the material toughness and where $\mathcal{G}^{\text {inc }}$ denotes the socalled incremental energy release rate. The second condition states that the tensile stress $\sigma$ acting along the crack path prior to failure must exceed the tensile strength $\sigma_{\mathrm{c}}(\mathrm{MPa})$

$$
\sigma(r) \geq \sigma_{\mathrm{c}} \text { for } 0 \leq r \leq l
$$

In the examples we deal with, we assume that the length $l$ is known, it is the thickness of the inner ply in laminate composites (Figure 1 (left)) or the thickness of the coating in the $\mathrm{C} / \mathrm{S}$ system (Figure 1 (right)), $l=e$. In that case, under a monotonic loading, one of the two 
conditions is generally fulfilled first and it is the other one that governs crack(s) initiation. At a given load, multi-cracking can occur if the stress condition governs, then the energy condition fulfils $\mathcal{G}^{\text {inc }}(l)>\mathcal{G}_{\text {Ic }}$ and the maximum number of cracks $n$ is such that

$$
\mathcal{G}^{\text {inc }}(n l) \geq \mathcal{G}_{\text {Ic }} \text { and } \mathcal{G}^{\text {inc }}((n+1) l)<\mathcal{G}_{\text {Ic }}
$$

provided the stress condition is fulfilled for all the cracks.

Before presenting an approach based on a representative cell and investigating more thoroughly various experiments, a simple example is given below to highlight the influence of the length of the specimens on the multi-cracking mechanism.

\subsection{A simple example of multi-cracking}

This example looks much more like a thought experiment, something like a simplified single fiber fragmentation test (Tripathi and Jones, 1998) for instance. Imagine an elastic rod of length $L$ and cross-section $S$ coated with a thin layer of an unbreakable resin, whose role is only to maintain the integrity of the structure. This rod is submitted to a uniaxial tension $\sigma_{\mathrm{a}}$ (Figure 2) by prescribing a longitudinal strain.

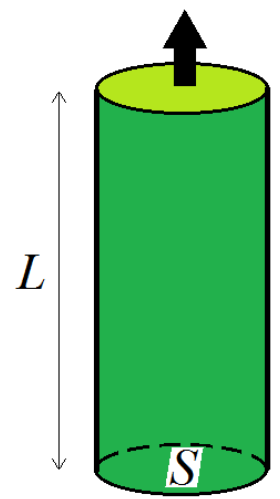

Figure 2. Schematic view of the rod in tension.

The potential energy $\boldsymbol{w}^{\mathrm{P}}$ stored in the structure can be written

$$
\boldsymbol{w}^{\mathrm{P}}=\frac{1}{2} S L \frac{\sigma_{\mathrm{a}}^{2}}{E}
$$

where $E(\mathrm{MPa})$ is the Young modulus of the material forming the rod. At failure the rod is completely broken and there is no longer any potential energy thus the change in potential energy $-\Delta \boldsymbol{w}^{\mathrm{P}}$ is

$$
-\Delta \boldsymbol{w}^{\mathrm{P}}=\boldsymbol{w}^{\mathrm{P}}=\frac{1}{2} S L \frac{\sigma_{\mathrm{a}}^{2}}{E}
$$

The necessary energy condition for fracture is then

$$
-\Delta \boldsymbol{w}^{\mathrm{P}} \geq \mathcal{G}_{\mathrm{Ic}} S \Rightarrow \sigma_{\mathrm{a}} \geq \sqrt{\frac{2 E \mathcal{G}_{\mathrm{Ic}}}{L}}
$$


The above inequality contains a paradox, the longer the specimen, the smaller the applied load triggering fracture. This paradox disappears when the stress condition is added (the tensile stress is constant throughout the rod)

$$
\sigma_{\mathrm{a}} \geq \sigma_{\mathrm{c}}
$$

The conditions (6) and (7) together define a transition length $L_{0}$

$$
L_{0}=\frac{2 E \mathcal{G}_{\mathrm{Ic}}}{\sigma_{\mathrm{c}}^{2}}
$$

For specimens shorter than this length, fracture is governed by the energy condition (6), the critical value of $\sigma_{\mathrm{a}}$ increases as $L$ becomes smaller and there is no excess energy production. Whereas for larger specimens it is the stress condition (7) that takes over, $\sigma_{\mathrm{a}}$ keeps constant and once the stress condition (7) is reached, it holds true throughout the specimen for any crack location. In addition there may be production of excess energy $\Delta \boldsymbol{w}^{\mathrm{E}}$

$$
\Delta \boldsymbol{w}^{\mathrm{E}}=-\Delta \boldsymbol{w}^{\mathrm{P}}-\boldsymbol{\mathcal { G }}_{\mathrm{Ic}} S=\mathcal{G}_{\mathrm{Ic}} S \frac{L-L_{0}}{L_{0}}
$$

If this extra energy cannot be dissipated in kinetic energy because of the confinement of the rod, then it is assumed that it is consumed by creating new cracks

$$
n=1+\operatorname{int}\left(\frac{L-L_{0}}{L_{0}}\right)
$$

where the operator "int" extracts the integer part of a real number and $n$ is the total number of cracks. Obviously, if the excess energy is not completely dissipated by cracking, $n$ is an upper bound of the number of cracks that can be created.

\section{The representative cell $(\mathrm{RC})$}

The multi-cracking phenomenon can give rise to a large number of cracks (some hundreds in the cases studied by Dalmas et al. (2016)), this difficulty coupled with the slenderness of the layers under consideration can make the calculations highly time consuming and even impossible to carry out. In order to get rid of the length of the specimens and to be independent of the number of cracks, the structure is modelled as a periodic distribution of RC's (Figure 3). 

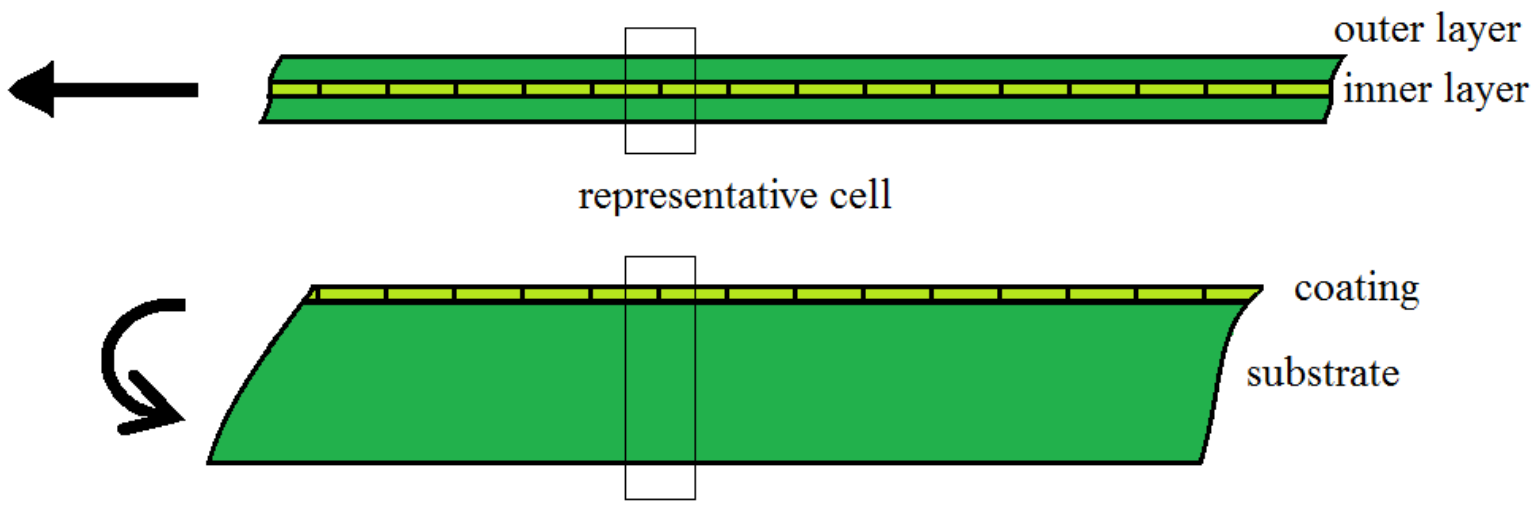

Figure 3. The RC extracted from the cross-ply laminate (top) and from the C/S system (bottom). The $\mathrm{C} / \mathrm{S}$ system is not on the right scale, the coating thickness is much smaller than that of the substrate.

Figure 4 shows details of the RC's. The two distances $c$ and $c^{\prime} \leq c$ are parameters of the model. The left frames are used to analyze the occurrence of the first family of cracks whose spacing is $2 c$ (crack density $d=1 / 2 c \mathrm{~mm}^{-1}$ ) and the right one for the subsequent subdivisions leading to a spacing between cracks equal to $c^{\prime}$ (crack density $d=1 / c^{\prime}$ ). The mechanical loadings of the specimens (tension for the cross-ply laminate and bending for the $\mathrm{C} / \mathrm{S}$ system) are transmitted, once and for all thanks to linearity, to the RC through a prescribed horizontal unit strain along the left boundary while the vertical displacement remains free: $u_{1}=c$ (or $c^{\prime}$ ) in the tensile case (Figure 4 (top)), $u_{1}=2 x_{2} c /(b+e)$ (or $2 x_{2} c^{\prime} /(b+e)$ ) in the bending case (Figure 4 (bottom), the origin being on the mid-plane). The upper and lower boundaries are traction free and the right one is a symmetry axis, since only one half of the RC is used for the calculations. Due to the thinness of the coating, the bending is not really perturbed by the crack in the right frame and no additional correction (Leguillon et al., 2016) is needed when analyzing the subdivisions (bottom right frame).
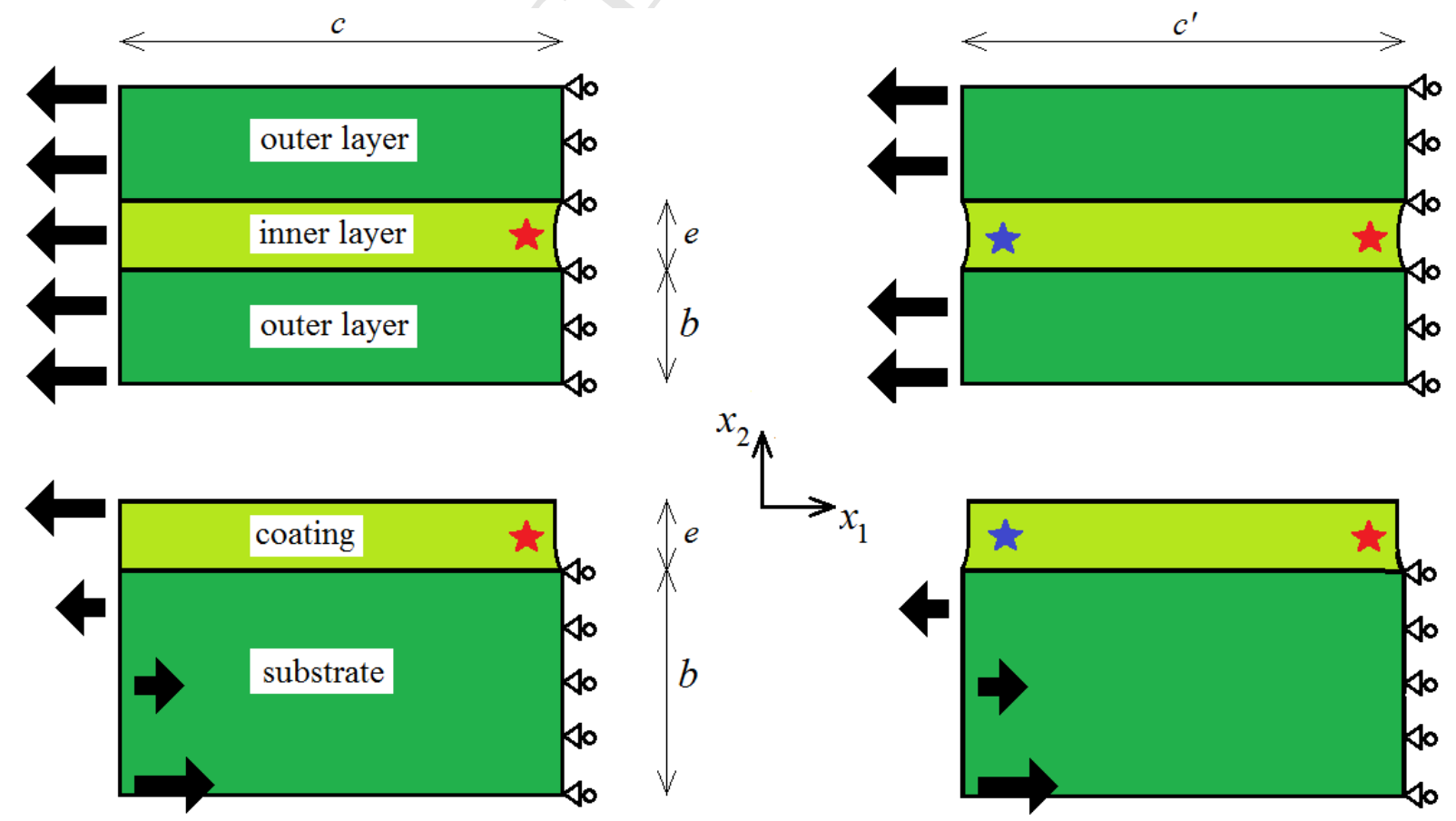
Figure 4. One half of the RC of the cross-ply laminate in tension (top) and the C/S system in bending (bottom); for the analysis of the occurrence of the first family of cracks (left) and for the subsequent subdivisions (right). Arrows are the prescribed displacements, the red stars show the location of the new cracks, the blue ones that of the previous cracks. Again, the $\mathrm{C} / \mathrm{S}$ system is not on the right scale.

In a first step the $\mathrm{CC}$ is applied to the left cells of Figure 4 to predict the onset of the first cracks and their spacing that is assumed to be constant. The change in potential energy $-\Delta \boldsymbol{W}^{\mathrm{P}}(c)$ in the cell between the uncracked and cracked states and the tensile component of the stress field along the crack path (i.e. through the thickness of the inner layer or of the coating) prior to the onset are computed using FE for a unit prescribed strain and for different cell sizes $c$. The $\mathrm{CC}$ allows determining the critical applied strain at onset $\varepsilon_{\mathrm{c}}(c)=\max \left(\varepsilon_{\mathrm{e}}, \varepsilon_{\mathrm{s}}\right)$ where $\varepsilon_{\mathrm{e}}$ and $\varepsilon_{\mathrm{s}}$ are the prescribed strains fulfilling respectively the energy and the stress condition for a given $c$. The critical strain $\varepsilon_{\mathrm{c}}$ function of the cell size is shown in Figure 5, it corresponds to Parvizi et al. experiments (1978) with an inner ply thickness $e=0.4 \mathrm{~mm}$ (see Figure 1 (left) and Section 4.1). Obviously, this critical strain remains almost constant on a wide domain of long cells, roughly for $c \geq 5 \mathrm{~mm}$. The value $c=20 \mathrm{~mm}$ is arbitrarily selected to initiate the process but it can be any one larger than $5 \mathrm{~mm}$ with a weak influence on the next calculations as seen later on.

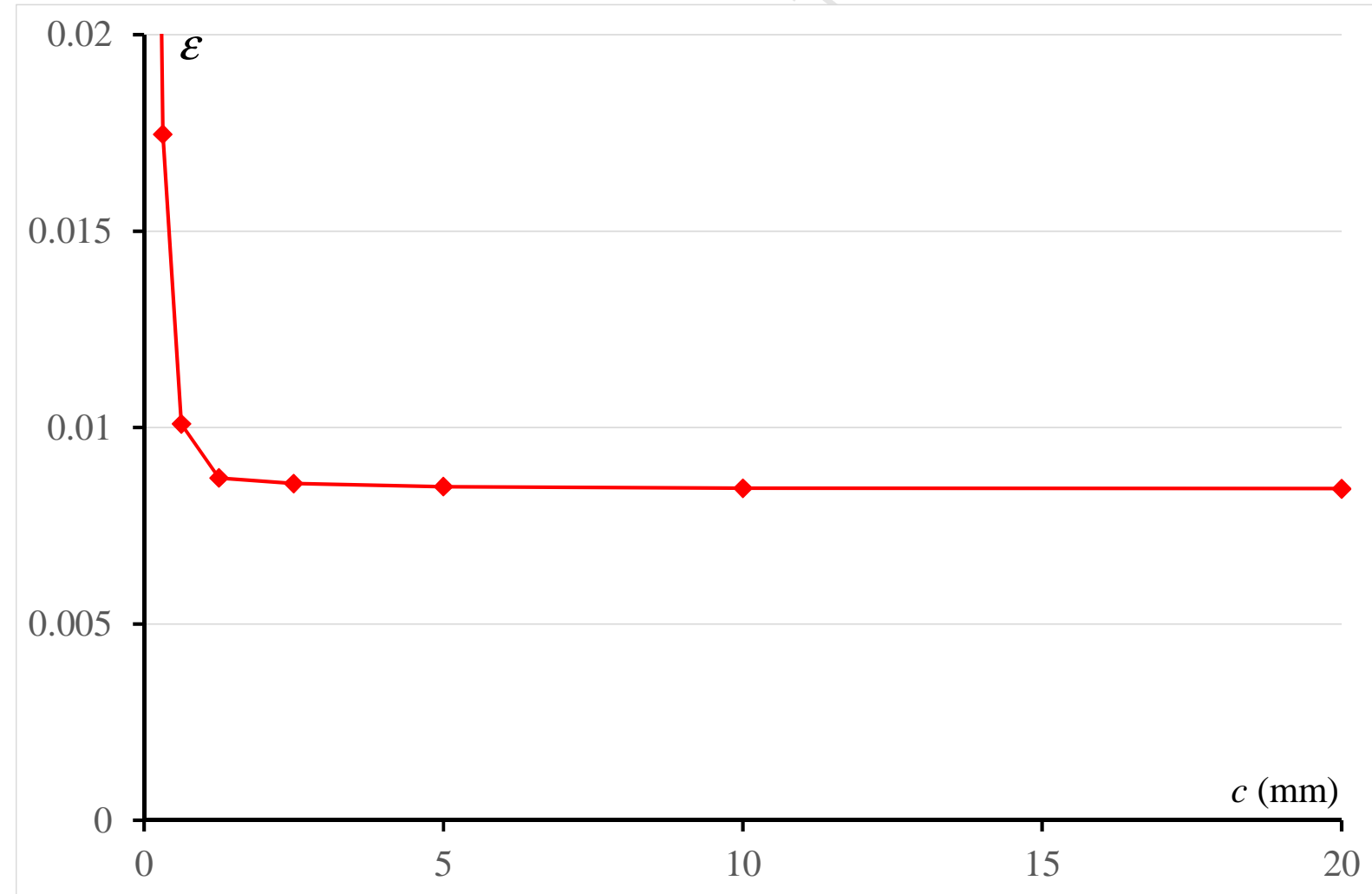

Figure 5. The critical applied strain $\varepsilon_{\mathrm{c}}$ at the onset of the first group of cracks function of the size of the RC, using Parvizi et al. parameters (Section 4.1) with $e=0.4 \mathrm{~mm}$.

In the next step, the criterion is applied to the right cells of Figure 4 with $c^{\prime}=c=20 \mathrm{~mm}$ in the same manner in order to determine the prescribed strain triggering the subdivision of the initial crack spacing. As a consequence of the assumption of periodicity, new cracks occur midway between existing cracks (Garrett and Bailey, 1977), the number of cracks doubles at 
each step. This point will be discussed in Sections 4.2 and 5. Then, the procedure is iterated, taking $c^{\prime}$ equal to one half of that of the previous step (i.e. $c^{\prime}=20,10,5,2.5 \ldots \mathrm{mm}$ ). It is illustrated in Figure 6, where, as expected from the flatness of the curve in Figure 5, the crack density increases rapidly when slightly increasing the load.

Indeed, considering Figure 5, due to the flatness of the curve, it is not easy to determine accurately the point where the curve starts to increase. It seems that $c=5 \mathrm{~mm}$ is a lower bound, as a consequence the initial crack density is smaller or at the maximum equal to $d=1 / 2 c=0.1 \mathrm{~mm}^{-1}$. Anyway, this choice has not a big influence and almost do not alter the curve showing the crack density as a function of the applied strain (Figure 6). Indeed, if a higher value is selected to initiate the process (as done here with $c=20 \mathrm{~mm}$ ), it is observed a rapid increase of the crack density, up to the value where the curve of Figure 5 is no longer flat.

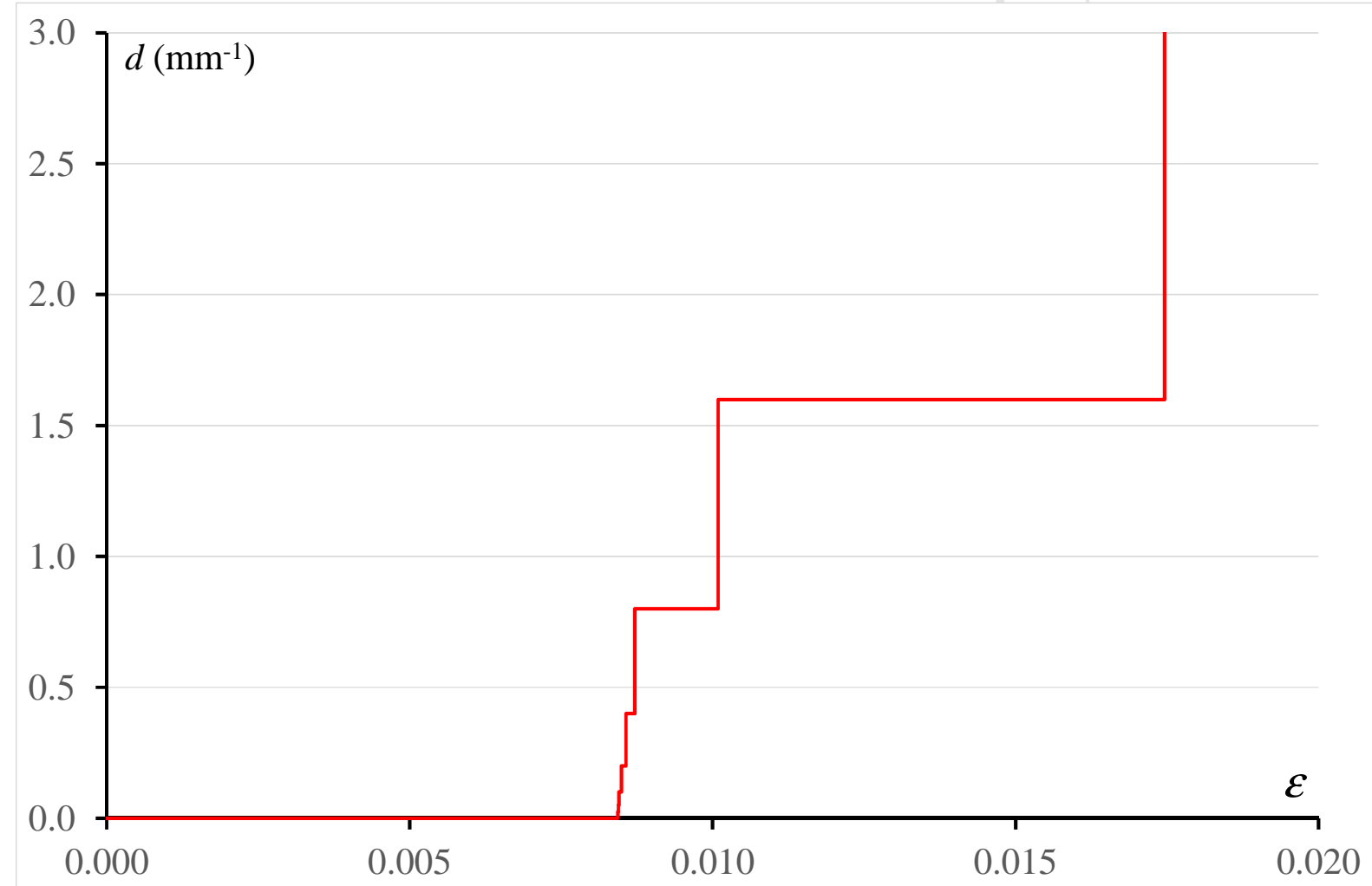

Figure 6. The crack density $d$ function of the increasing applied strain, using Parvizi et al. parameters (Section 4.1) with $e=0.4 \mathrm{~mm}$.

\section{Numerical results}

\subsection{Comparison with the experiments on cross-ply laminates by Parvizi et al. (1978)}

The tensile tests carried out by Parvizi et al. (1978) are depicted in Figure 1 (left). The outer plies thickness is $b=0.5 \mathrm{~mm}$ and the inner ply thickness $e$ varies from 0.1 to $4 \mathrm{~mm}$. The different plies are made of a glass-epoxy composite which material parameters are: longitudinal Young's modulus $E_{1}=42 \mathrm{GPa}$, transverse Young's modulus $E_{\mathrm{t}}=14 \mathrm{GPa}$, longitudinal shear modulus $G_{1}=10 \mathrm{GPa}$, transvers shear modulus $G_{t}=6.2$, GPa, longitudinal 
Poisson's ratio $v_{1}=0.13$, transverse Poisson's ratio $v_{\mathrm{t}}=0.4$, tensile strength $\sigma_{\mathrm{c}}=84 \mathrm{MPa}$, toughness $\boldsymbol{\mathcal { G }}_{\mathrm{Ic}}=0.24 \mathrm{MPa} \mathrm{mm}$.

Using a shear-lag model to describe the stress state of a cross-ply laminate $\left[0,90_{\mathrm{x}}\right]_{\mathrm{S}}$ under tension, Parvizi et al. (1978) show that the change in potential energy $-\Delta \boldsymbol{w}^{\mathrm{P}}$ prior to and following the onset of the first transverse crack in the inner layer, can be written

$$
-\Delta \boldsymbol{w}^{\mathrm{P}}=A \sigma_{\mathrm{i}}^{2} e^{2} w
$$

Where $A\left(\mathrm{MPa}^{-1}\right)$ is a scaling coefficient, $e$ and $w$ denote respectively the inner ply thickness and the width of the specimen and $\sigma_{\mathrm{i}}$ is the tensile stress in the inner layer.

The energy criterion gives

$$
A \sigma_{\mathrm{i}}^{2} e^{2} w \geq \boldsymbol{\mathcal { G }}_{\mathrm{Ic}} e w \Rightarrow \sigma_{\mathrm{i}} \geq \sqrt{\frac{\mathcal{\mathcal { G }}_{\mathrm{Ic}}}{A e}}
$$

The above inequality again contains a paradox, the thicker the inner layer, the smaller the applied load triggering transverse cracking. Of course, this paradox disappears when the stress condition is added. In their model, the tensile stress is constant in the inner layer and the stress condition leads to

$$
\sigma_{\mathrm{i}} \geq \sigma_{\mathrm{c}}
$$

As above (Section 2.2), the conditions (12) and (13) demarcate two zones and the transition in between is defined by the thickness $e_{0}$

$$
e_{0}=\frac{\mathcal{G}_{\text {Ic }}}{A \sigma_{\mathrm{c}}^{2}}
$$

For lower values of $e$ the energy criterion predominates and for higher values fracture is governed by the stress condition.

Figure 7 shows a comparison between these experiments and the simulations carried out using the CC applied to the RC. Obviously this simplified geometry is perfectly able to capture the transition between the thicknesses where the energy condition governs and those where the stress condition predominates. Moreover, the predicted values agree quite well with the measurements. 


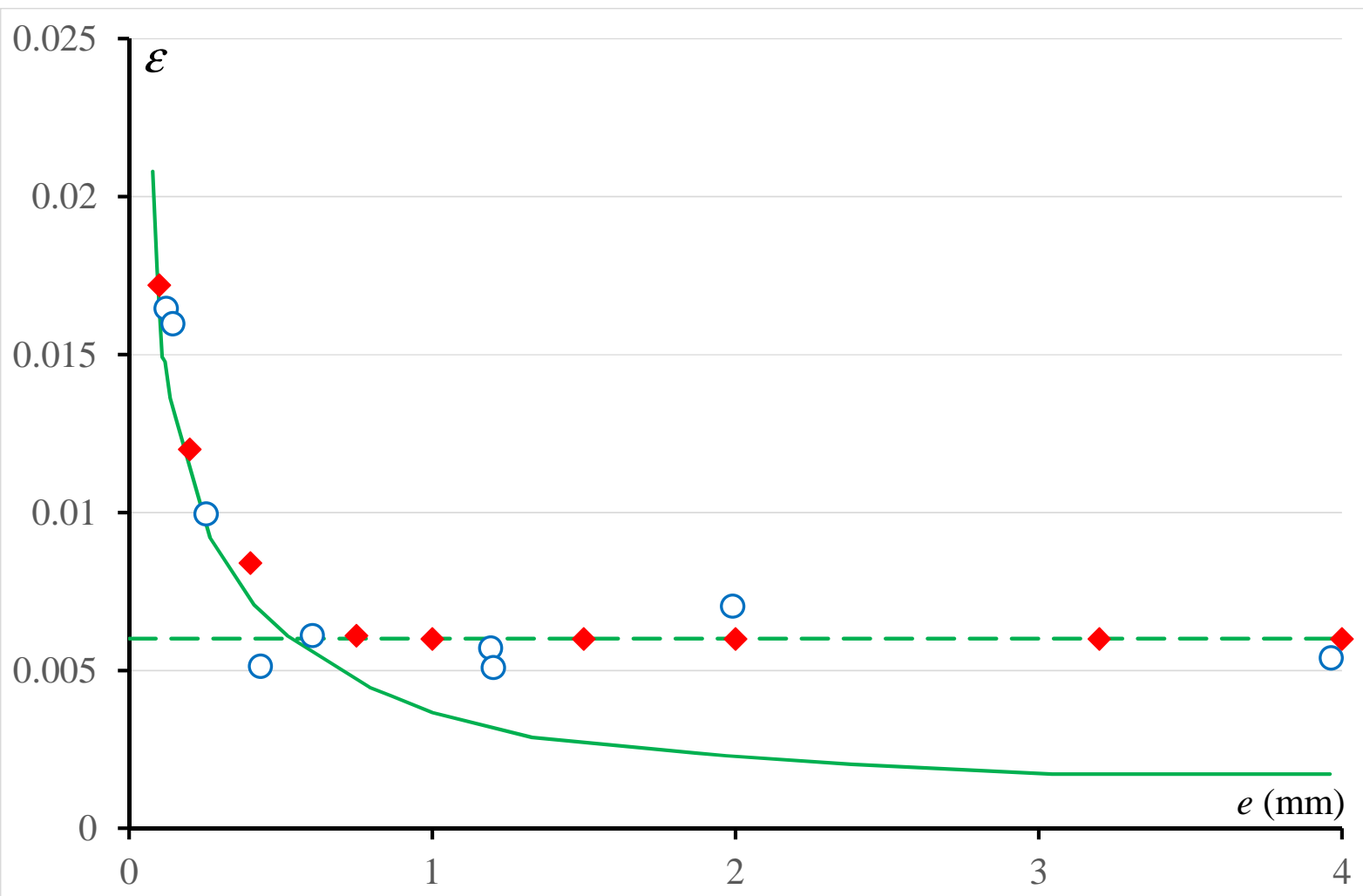

Figure 7. Applied strain at onset of the first $\operatorname{crack}(\mathrm{s})$ function of the inner ply thickness. Comparison between Parvizi et al. experiments (blue open circles) and the present simulations (red solid diamonds). The horizontal dashed line is the stress condition and the hyperbolic solid one the energy condition (as plotted by Parvizi et al.).

\subsection{Comparison with the analysis of Laws and Dvorak on cross-ply laminates (1988)}

Laws and Dvorak (1988) analyzed results of experiments conducted by Highsmith and Reifsnider (1982) on a cross-ply laminate $\left[0,90_{3}\right]_{\mathrm{S}}$ made of glass-epoxy (Figure 1 (left)) with the following material parameters: longitudinal Young's modulus $E_{1}=41.7 \mathrm{GPa}$, transverse Young's modulus $E_{\mathrm{t}}=13.3 \mathrm{GPa}$, longitudinal shear modulus $G_{1}=3.4 \mathrm{GPa}$, transvers shear modulus $G_{t}=4.6, \mathrm{GPa}$, longitudinal Poisson's ratio $v_{1}=0.3$, transverse Poisson's ratio $v_{\mathrm{t}}=$ 0.4 , tensile strength $\sigma_{\mathrm{c}}=65 \mathrm{MPa}$, toughness $\mathcal{G}_{\text {Ic }}=0.19 \mathrm{MPa} \mathrm{mm}$ (as predicted by Laws and Dvorak). The thickness of the inner ply is $e=1.2 \mathrm{~mm}$ and that of the outer ones $b=0.2 \mathrm{~mm}$. They proposed a prediction of the crack density, as a function of the increasing applied load, based on the tensile stress in the inner ply and a probability on the location of the onset of a new crack between two existing ones. Two cases are illustrated in Figure 8: (i) the crack is guaranteed to occur at the midpoint (green solid line), (ii) the crack occurs randomly in the segment in between existing cracks (green dashed line). It is compared to the experiments (blue open circles) and to the prediction based on the RC geometry and the CC (red solid line). The authors claimed that the hypothesis of randomness due to the presence of flaws is crucial in the prediction. It is certainly quite true for large cracks spacing (small crack density) but no longer is when it becomes smaller, the profile of the stress field in the length with a peak in the middle playing a key role in the emergence of cracks at midway. 


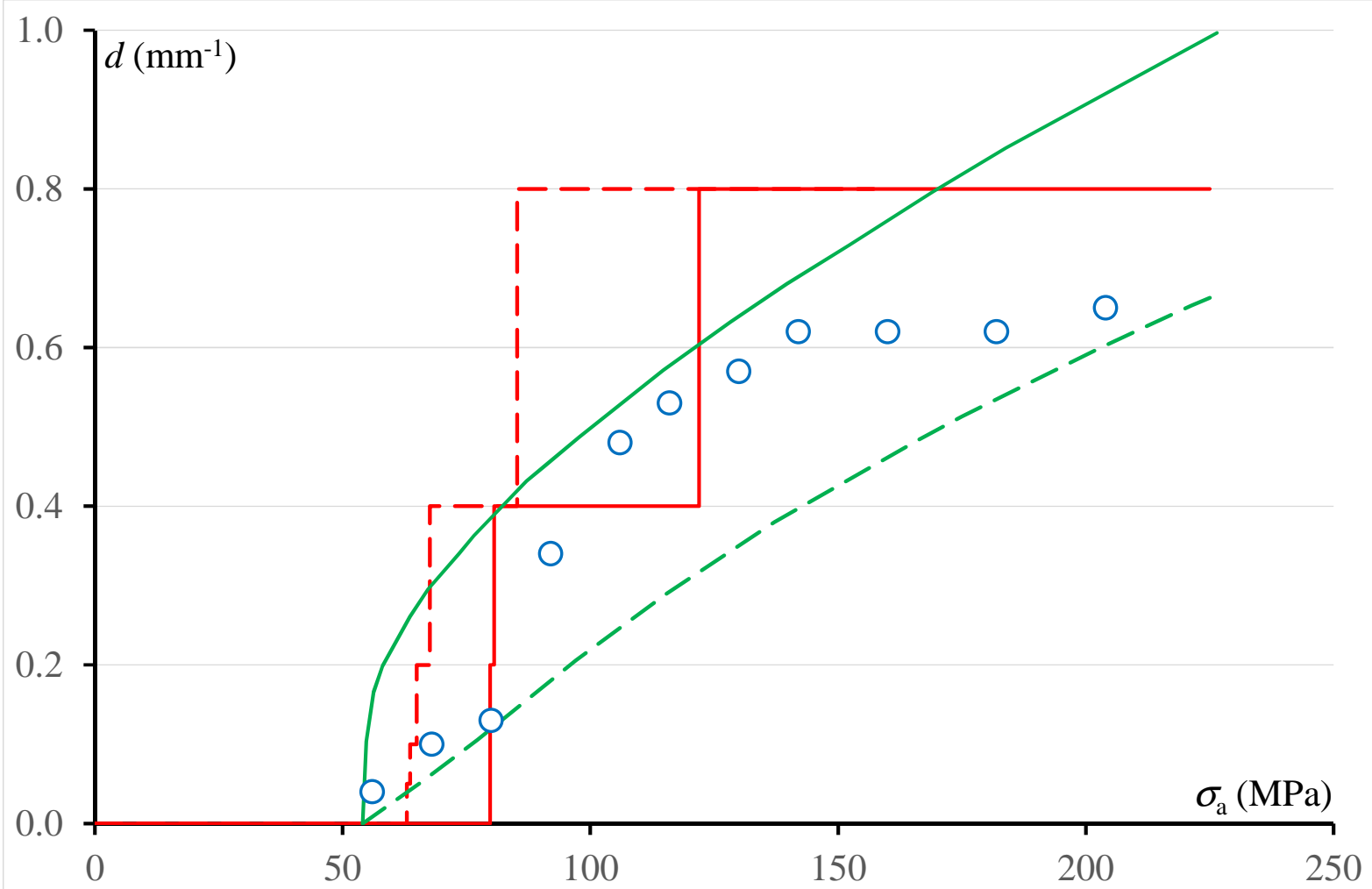

Figure 8. Crack density $d$ function of the increasing applied load $\sigma_{\mathrm{a}}$. Comparison between the experiments by Highsmith and Reifsnider (blue open circles), the predictions of Laws and Dvorak (green solid and dashed lines) and the prediction based on the RC: applying the CC (red solid line), applying the single energy condition (dashed red line).

As the thickness of the inner layer is rather large, the stress condition governs for a wide range of cell sizes. Then, not surprisingly, a comparison with a pure energetic approach (red dashed line in Figure 8) shows that this latter tends to underestimate the critical load triggering $\operatorname{crack}(\mathrm{s})$ initiation and further subdivisions. Anyway, the agreement between the experiments and the $\mathrm{CC}$ is rather good even if the prediction tends to slightly overestimate the crack density. The crack density $d=0.8 \mathrm{~mm}^{-1}$ is a limit in our model, the stress condition can no longer be fulfilled for closer cracks, this means that the layer is saturated, while this saturation mechanism seems more difficult to capture in the model of Laws and Dvorak.

\subsection{Comparisons with the experiments on cross-ply laminates by Huchette (2005)}

Huchette (2005) has completed an important campaign of observations of transverse cracking in cross-ply laminates made of carbon-epoxy T700/M21 composite (Hexcel® Composites) in tension (Figure 1 (left)) with the following material parameters: longitudinal Young's modulus $E_{1}=116 \mathrm{GPa}$, transverse Young's modulus $E_{\mathrm{t}}=8.1 \mathrm{GPa}$, longitudinal shear modulus $G_{1}=4.5 \mathrm{GPa}$, transverse shear modulus $G_{t}=4.5$, GPa, longitudinal Poisson's ratio $v_{1}=0.3$, transverse Poisson's ratio $v_{\mathrm{t}}=0.3$. The outer plies thickness is $b=0.52 \mathrm{~mm}$, and that of the inner ply is varied: $e=0.26,0.52,1.04,1.56 \mathrm{~mm}$.

Few information is available on the transverse fracture parameters and an attempt of identification is provided in Huchette (2005). It is based either on a stress or on an energy criterion but, clearly, the energy criterion will underestimate the critical loading for thick inner layers whereas, vice versa, the stress criterion will lead to underestimate the critical load 
for thin inner layers. In addition, some residual thermal stresses and a large scattering take place to blur the results.

Based on the CC, we have tried to identify the toughness of the inner ply on the experiments carried out on the thinner inner layer $e=0.26 \mathrm{~mm}$ (Figure 9) and symmetrically, identify the transverse tensile strength on experiments on the thicker inner layer $e=1.56 \mathrm{~mm}$.

Figure 9 shows the comparison between predictions using the RC geometry and experiments for $e=0.26 \mathrm{~mm}$ after having identified $\mathcal{G}_{\mathrm{Ic}}=0.7 \mathrm{MPa} \mathrm{mm}$. The identification was done to the naked eye to match "at the best" with experiments. This value is far higher than the value 0.2 MPa mm proposed by Huchette (2005), but not unrealistic since in this composite the matrix toughness is improved by adding thermoplastic particles. Note that, around this value, the prediction is insensitive to variations of the tensile strength below $200 \mathrm{MPa}$ (whereas the identified value is around $125 \mathrm{MPa}$ as seen further on), the energy condition is governing.

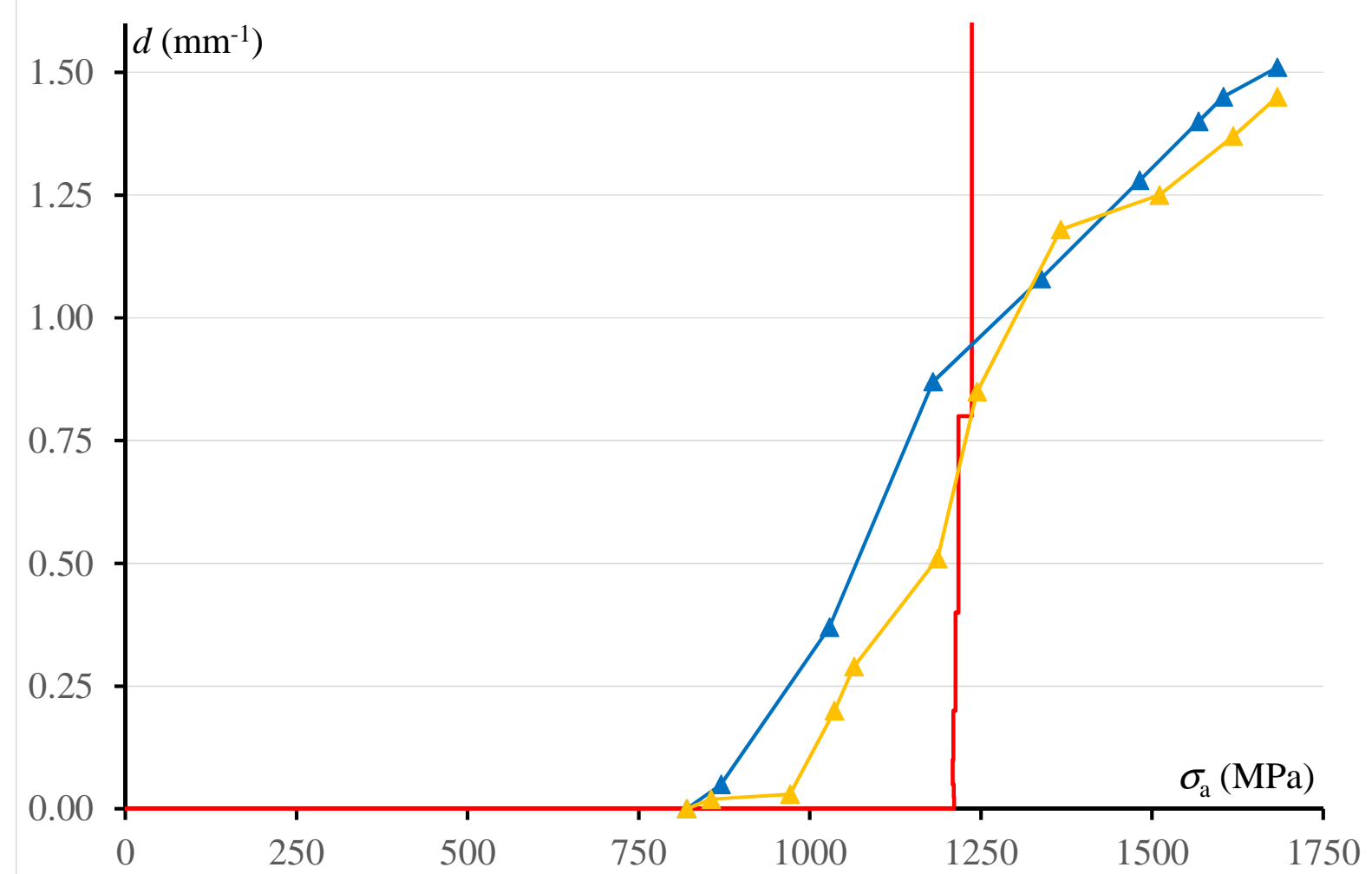

Figure 9. The crack density $d$ function of the applied load $\sigma_{\text {a }}$ for $e=0.26 \mathrm{~mm}$. The red solid line is the prediction after having identified the toughness $\mathcal{G}_{\text {Ic }}=0.7 \mathrm{MPa} \mathrm{mm}$ of the inner ply (with $\sigma_{\mathrm{c}}<200 \mathrm{MPa}$ ). It is compared to the experiments (solid lines with triangular marks).

Figure 10 shows the comparison between predictions using the RC geometry and experiments for $e=1.56 \mathrm{~mm}$ after having identified $\sigma_{\mathrm{c}}=125 \mathrm{MPa}$. Again, the identification was done to match "at the best" with experiments taking into account the scattering. It is a little higher than the value $85 \mathrm{MPa}$ proposed by Huchette (2005). This value being fixed at $125 \mathrm{MPa}$, the prediction is completely insensitive to variations of the toughness below $1.25 \mathrm{MPa} \mathrm{mm}$ (whereas it was seen earlier that a realistic value is around $0.7 \mathrm{MPa} \mathrm{mm}$ ), obviously the stress condition is governing. 


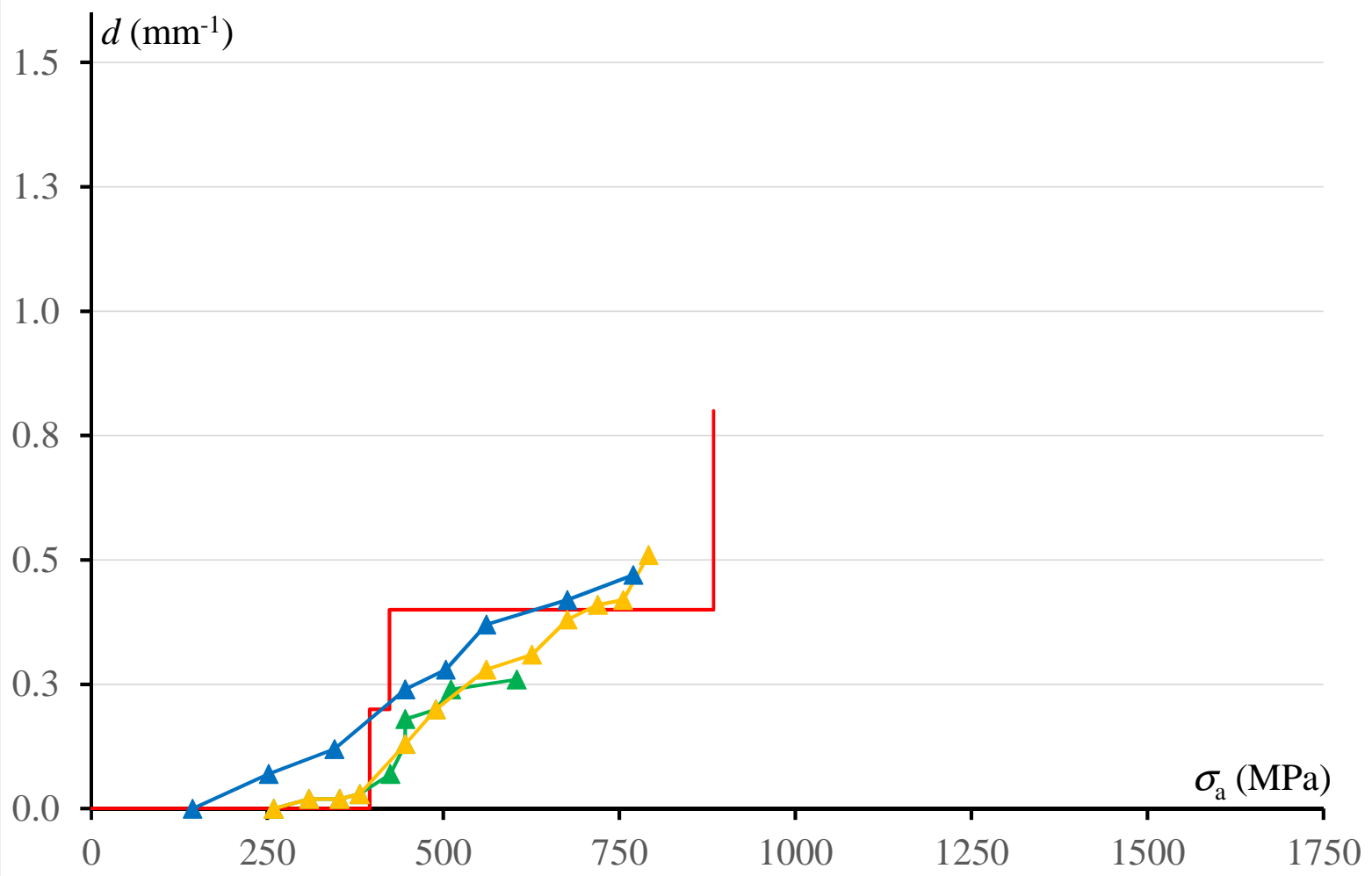

Figure 10. The crack density $d$ function of the applied load $\sigma_{\mathrm{a}}$ for $e=1.56 \mathrm{~mm}$. The red solid line is the prediction after having identified the transverse tensile strength $\sigma_{\mathrm{c}}$ of the inner ply (with $\mathcal{G}_{\text {Ic }}<1.25 \mathrm{MPa} \mathrm{mm}$ ). It is compared to the experiments (solid lines with triangular marks).

Once the transverse fracture parameters are identified $\mathcal{G}_{\text {Ic }}=0.7 \mathrm{MPa} \mathrm{mm}, \sigma_{\mathrm{c}}=125 \mathrm{MPa}$, these values can be used to carry out a comparison for the intermediate thicknesses of the inner ply $e=0.52 \mathrm{~mm}$ and $e=1.04 \mathrm{~mm}$. It is illustrated in Figures 11 and 12. There is a satisfying agreement between experiments and comparisons, even if in the case $e=1.04 \mathrm{~mm}$ the crack density tends to be overestimated.

All the figures are plotted at the same scale to better decipher, this allows to discern the very different scales at which cracking occurs, both on the vertical and horizontal axes between the two extreme cases shown in Figures 9 and 10. The crack density and the applied load at crack initiation are larger for thinner layers and the predictions substantially meet the orders of magnitude in all cases. 


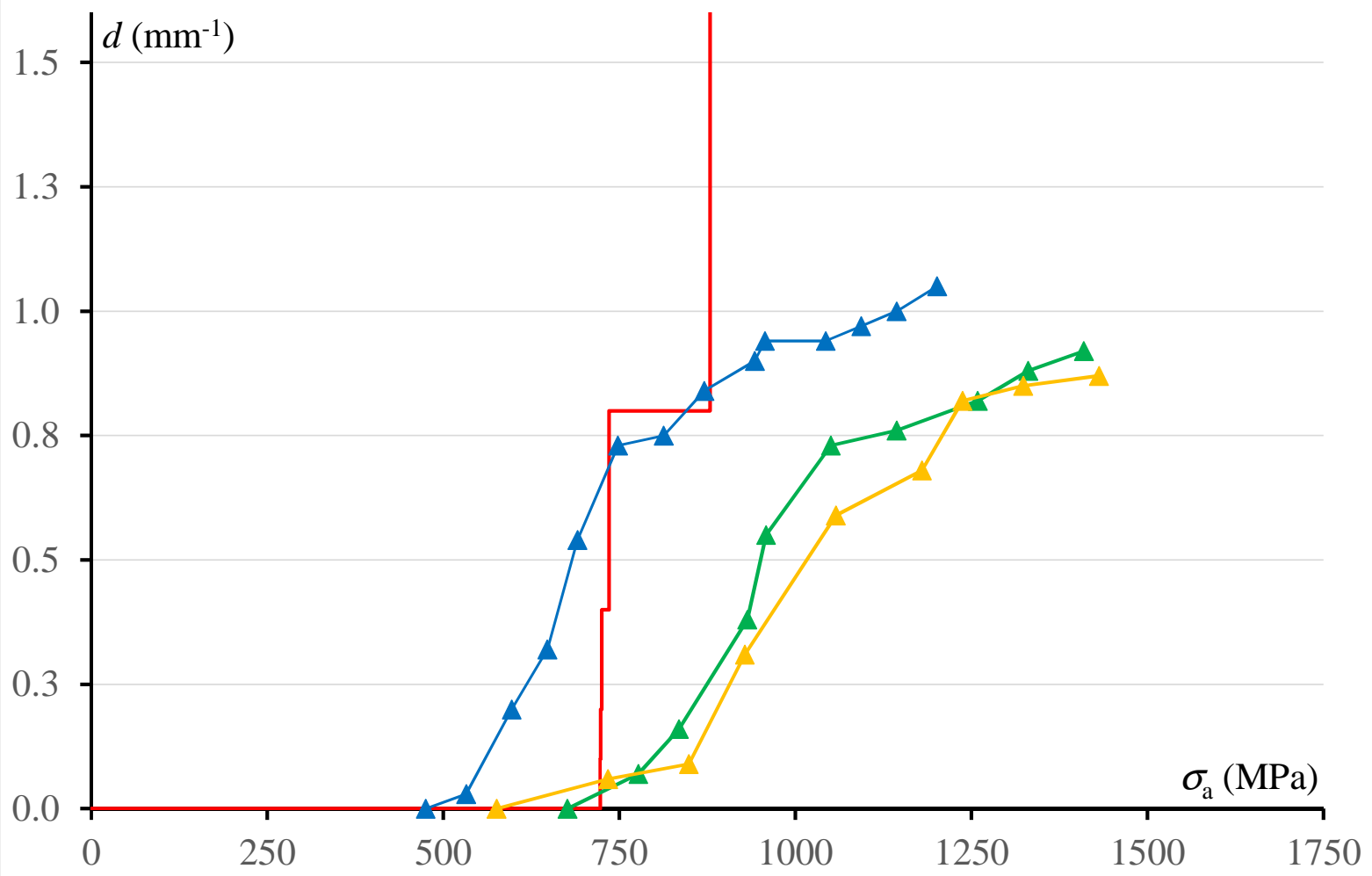

Figure 11. The crack density $d$ function of the applied load $\sigma_{\mathrm{a}}$ for $e=0.52 \mathrm{~mm}$. The red solid line is the prediction, it is compared to the experiments (solid lines with triangular marks).

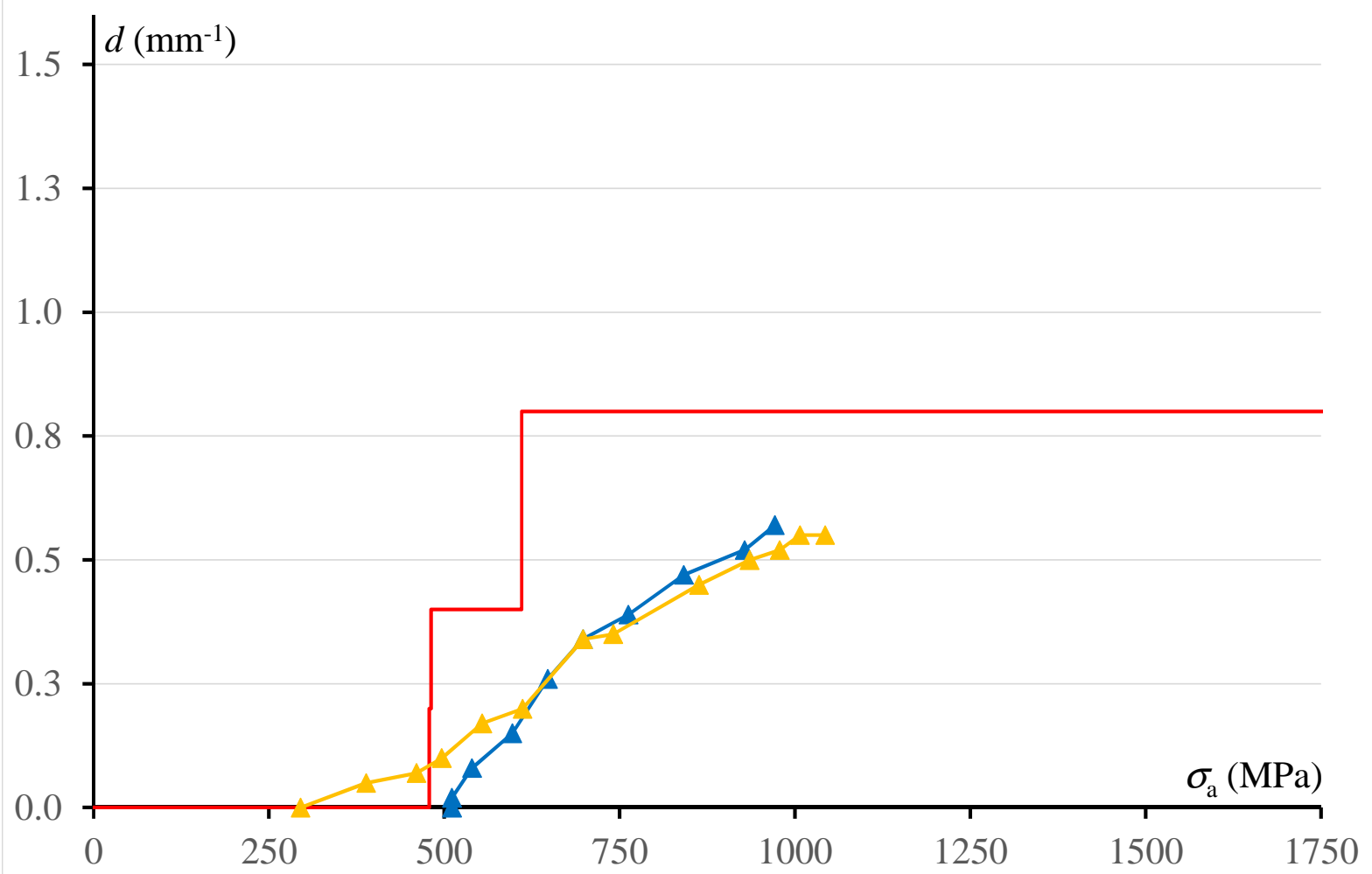

Figure 12. The crack density $d$ function of the applied load $\sigma_{\mathrm{a}}$ for $e=1.04 \mathrm{~mm}$. The red solid line is the prediction, it is compared to the experiments (solid lines with triangular marks). 
In these tests, several realizations are displayed and one can deduce the order of magnitude of the uncertainties associated with the measurements. However, the theoretical values proposed here fall satisfactorily within these uncertainties.

\subsection{Comparison with the experiments on coatings by Kim and Nairn (2000)}

The experiments conducted by Kim and Nairn (2000) are bending tests of coated substrates of polycarbonate (Figure 1 (right)), the so-called C/S system, the thickness of the substrate is $b=6 \mathrm{~mm}$, and that of the coating is far much smaller $e=0.125 \mathrm{~mm}$. Young's modulus and Poisson's ratio of the substrate are $E_{\mathrm{s}}=2.3 \mathrm{GPa}, v_{\mathrm{s}}=0.37$, Young's modulus and Poisson's ratio of the coating are $E_{\mathrm{c}}=1.9 \mathrm{GPa}, \boldsymbol{v}_{\mathrm{c}}=0.33$ and its toughness is $\boldsymbol{\mathcal { G }}_{\mathrm{Ic}}=0.8 \mathrm{MPa} \mathrm{mm}$ (for the $\mathrm{C} / \mathrm{S}$ system baked during $96 \mathrm{~h}$ ). As Kim and Nairn refer only to an energy condition (Hashin 1985), the tensile strength of the coating is not provided. It is estimated to a realistic value around $\sigma_{\mathrm{c}}=80 \mathrm{MPa}$ to fit at the best with the measurements.

Figure 13 compares the measurements of crack density to the predictions of the CC using the RC and that of Kim and Nairn (2000), as functions of the bending strain $\varepsilon_{\mathrm{b}}$. The agreement between them is good and our prediction meets the order of magnitude, but obviously the present prediction tends to overestimate the final crack density.

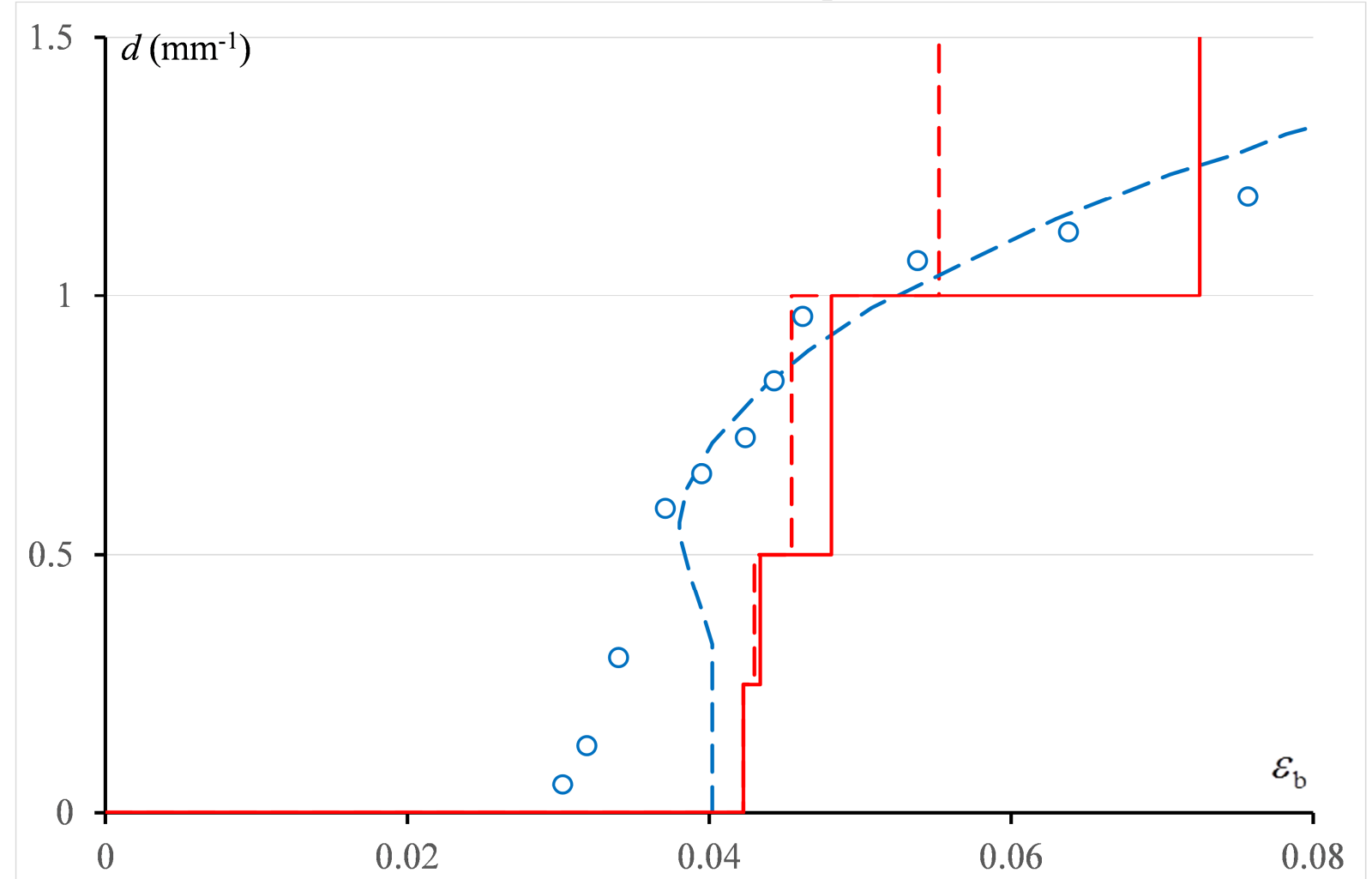

Figure 13. Crack density $d$ function of the bending strain $\varepsilon_{\mathrm{b}}$. Comparison between the experiments and the prediction of Kim and Nairn (respectively blue open circles and blue dashed line) and the prediction based on the $\mathrm{CC}$ and the RC: without delamination (red dashed line) and with delamination (red solid line).

The discrepancy observed in Figure 13 between the measurements and the predictions of the $\mathrm{CC}$ can originate in the presence of delamination at the interface between the coating and the 
substrate at the tip of the transverse crack as suggested by Ye et al. (1992) and Kotoul et al. (2010) for instance.

To this aim a short delamination is added at the tip of the transverse cracks once initiated (Figure 14). It is commonly admitted that the delamination length is of the order of the coating thickness $e$ as selected here (Leguillon and Martin, 2014). For the sake of simplicity, this delamination length is fixed once and for all, it is assumed that it does not evolve although it can slightly increase with the increasing load. Note that, during bending, prior to the transverse cracking, no tension acts on the interface, thus delamination necessarily occurs in two distinct stages: first a transverse cracking, then afterwards the delamination takes place due to the stress concentration at the tip of the transverse crack. Therefore, the whole process is governed by the transverse cracking and it is the only mechanism studied herein.

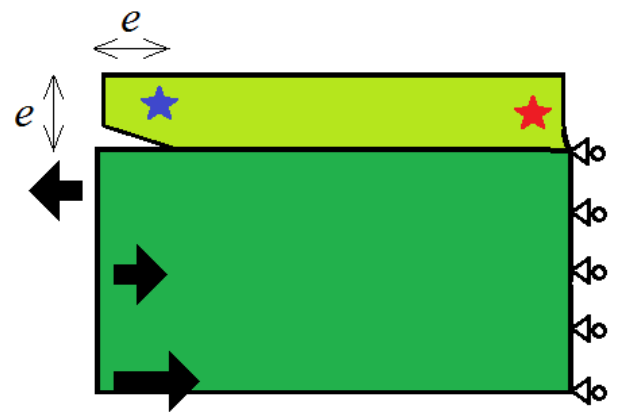

Figure 14. A short delamination at the tip of a previous transverse crack in the RC.

With this additional assumption, there is a better agreement between measurements and prediction based on the $\mathrm{CC}$ for large crack densities, as shown in Figure 13. The debonding tends to inhibit the creation of new cracks for short RC's. Moreover this should be a little more pronounced if the delamination length was increased with the load. This additional mechanism can also be invoked in the prediction of multi-cracking of cross-ply laminates where it is also observed that the $\mathrm{CC}$ tends to overestimate the crack density (Sections 4.2 and 4.3) and where, with no doubt, delamination takes place at the tip of the transverse cracks between the 0 deg. and the 90 deg. plies (Huchette, 2005).

Some authors (Ganne et al., 2002; Dalmas et al., 2016; Ben Cheikh, 2016) suggest in addition a plastic behavior of the substrate in the vicinity of the tip of the transverse cracks. As a consequence, an additional part of the extra-energy is consumed in another mechanism than fracture which necessarily diminishes the final crack density.

\section{Conclusion}

It is very difficult to predict accurately the mechanisms of multi-cracking in brittle thin layers and coatings. The main reason is that there is a large scattering in the experiments due to a random distribution of flaws. This is particularly true for the onset of the first cracks and the results of Parvizi et al. (1978) have been the focus of a controversy (Kelly, 1988): the observed phenomenon was it correctly described by their model or was it only related to a statistical effect (Weibull, 1951)? Both theories lead to rather similar conclusions and it is almost impossible to discriminate from the experiments. Indeed, it seems that the two effects cumulate as proposed in (Leguillon et al., 2015) to explain the difference between flexural and tensile strength.

Anyway, this randomness holds certainly true for large cracks spacing but is less when this spacing decreases. This because the tensile stress is no longer constant in the length of the RC and exhibits a peak in the middle, promoting the onset at this location. This assertion is 
confirmed by the model of Laws and Dvorak (1988). In Figure 8, the prediction using the assumption of a crack onset randomly located between existing ones matches the experiments for small crack densities, whereas the prediction based on cracks appearing midway is in a better agreement for high crack densities.

For simplicity reasons, the present model is based on the assumption of a crack onset midway in between already existing cracks. Nevertheless, even for the nucleation of the first $\operatorname{crack}(\mathrm{s})$, the calculated values agrees rather well with all kinds of experiments (see in particular Figure 7) for both thin (energy driven) and thick (stress driven) layers. There is no adjustable parameters in the $\mathrm{CC}$ and its prediction meets satisfactorily the orders of magnitude in describing the crack density as a function of the increasing applied load. Of course, its huge advantage lies in the use of the $\mathrm{RC}$ which dramatically reduces the volume of calculations to be performed while offering reliable results. This allows, among other things, to try a large number of RC lengths. With the option we have selected - at each step the length $c^{\prime}$ of the cell is one half of that at the previous step - the crack density doubles at each stage. This explain the staircase shape of the crack density prediction. An alternative could be to vary continuously the length $c^{\prime}$, starting with the initial value $c$, then the density prediction would be a continuous curve. But, of course, in that case the subdivision mechanism is not so clear, this approach could be considered as a method to smooth the curves in order to better resemble to the results of measurements.

In conclusion, it can be pointed out that it is difficult to draw up a general and synthetic rule for this kind of mechanism. It depends on many parameters: the relative thickness of the layers, the material properties of the components, the loading... There is for instance such a huge gap in the spacing of cracks when considering a ceramic such as alumina or a polymer binder or even geomaterials (Leguillon, 2013). Our goal was rather to develop a general approach relying on the coupled criterion to address these multi-cracking problems, even if it seems necessary to work on a case-by-case basis.

\section{References}

Andersons J., Modniks J., Leterrier Y., Tornare G., Dumont P., Månson J.A.E., 2008. Evaluation of toughness by finite fracture mechanics from crack onset strain of brittle coatings on polymers. Theor. Appl. Fract. Mech. 49, 151-157.

Bahr H.A., Weiss H.J., Bahr U., Hofmann M., Fischer G., Lampenscherf S., Balke H., 2010. Scaling behavior of thermal shock crack patterns and tunneling cracks driven by cooling or drying. J. Mech. Phys. Solids 58, 1411-1421.

Ben Cheikh I., 2016. Study of multi-cracking of brittle thin films and brittle/ductile multilayers on compliant substrate. 21st European Conference on Fracture, ECF21, 20-24 June 2016, Catania, Italy.

Beuth J.L., 1992. Cracking of thin films in residual tension. International Journal of Solids and Structures 29, 1657-1675.

Belytschko T., Loehnert S., Song J.H., 2008. Multiscale aggregating discontinuities: A method for circumventing loss of material stability. Int. J. Num. Meth. Engng. 73, 869894.

Dalmas D., Ben Cheikh I., Teisseire J., marthelot J., 2016. Experimental and numerical investigation of fracture in brittle multi-layers on flexible substrate. 21st European Conference on Fracture, ECF21, 20-24 June 2016, Catania, Italy.

Fu Y., Zhang X.C., Xuan F.Z., Tu S.T., Wang Z.D., 2013. Multiple cracking of thin films due to residual stress combined with bending stress. Comp. Mater. Sci. 73, 113-119. 
Ganne T., Crepin J., Serror S., zaoui A., 2002. Cracking behaviour of PVD tungsten coatings deposited on steel substrates. Acta Mater. 50, 4149-4163.

Garcia I.G., Mantic V., Blazquez A., Paris F., 2014. Transverse crack onset and growth in cross-ply $[0 / 90]_{S}$ laminates under tension. Application of a coupled stress and energy criterion. Int. J. Solids Structures 51, 3844-3856.

Garrett K.W., Bailey J.E., 1977. Multiple transverse fracture in $90^{\circ}$ cross-ply laminates of a glass fibre-reinforced polyester. J. Mater. Sci. 12, 157-168.

Ghosh S., Bai J., Raghavan P., 2007. Concurrent multi-level model for damage evolution in microstructurally debonding composites. Mech. Mater. 39, 241-266.

Greco F., Leonetti L., Nevone Blasi P., 2014. Adaptive multiscale modeling of fiberreinforced composite materials subjected to transverse microcracking. Composite Structures 113, 249-263.

Greco F., Leonetti L., Lonetti P., Nevone Blasi P., 2015. Crack propagation analysis in composite materials by using moving mesh and multiscale techniques. Computers and Structures 153, 201-216.

Hashin Z., 1985. Analysis of cracked laminates: a variational approach. Mech. Mater. 4, 121136.

Hashin Z., 1996. Finite thermoelastic fracture criterion with application to laminate cracking analysis, J. Mech. Phys. Solids 44, 1129-1145.

Highsmith A.L., Reifsnider K.L., 1982. Stiffness reduction in mechanisms in composite laminates. ASTM STP 575, 103.

Huchette C., 2005. Sur la complémentarité des approches expérimentales et numériques pour la modélisation des mécanismes d'endommagement des composites stratifiés. PhD dissertation, University Pierre and Marie Curie, Paris.

Jiang C.P., Wu X.F., Li J., Song F., Shao Y.F., Xu X.H, Yan P., 2012. A study of the mechanism of formation and numerical simulations of crack patterns in ceramics subjected to thermal shock. Acta Mater. 60, 4540-4550.

Kashtalyan M., Sinchuk Y., Piat R., Guz I., 2016. Analysis of multiple cracking in metal/ceramic composites with lamellar microstructure. Arch. Appl. Mech. 86, 177-188.

Kelly A., 1988. Compromise and attainment of mechanical properties in all brittle systems. In: Proceedings of the 9th RISO Int. Symp. in Metallurgy and Material Science, 5-9 September 1988, RISO Natl. Lab., Roskilde, Denmark.

Kotoul M., Ševeček O., Profant T., 2010. Analysis of multiple cracks in thin coating on orthotropic substrate under mechanical and residual stresses. Engng. Fract. Mech. 77, 229248.

Kim S.Y., Nairn J.A., 2000. Fracture mechanics analysis of coating/substrate systems. Part I: Analysis of tensile and bending experiments. Part II: Experiments in bending. Engng. Fract. Mech. 65, 573-593, 595-607.

Laws N., Dvorak G., 1988. Progressive transverse cracking in composite laminates. J. Comp. Mater. 22, 900-916.

Leguillon D., 2002. Strength or toughness? A criterion for crack onset at a notch, Eur. J. Mech. A/Solids 21, 61-72.

Leguillon D., 2013. A simple model of thermal crack pattern formation using the coupled criterion. C. R. Mécanique 341, 538-546.

Leguillon D., Haddad O., Adamowska M., Da Costa P., 2014. Crack pattern formation and spalling in functionalized thin films. Procedia Materials Science, 3, 104-109.

Leguillon D., Martin E., Lafarie-Frenot M.C., 2015. Flexural vs. tensile strength in brittle materials. C.R. Mécanique 343, 275-281. 
Leguillon D., Lafarie-Frenot M.C., Pannier Y., Martin E., 2016. Prediction of the surface cracking pattern of an oxidized polymer induced by residual and bending stresses. Int. J. Solids and Structures 91, 89-101.

Leguillon D., Martin E., 2014. Crack nucleation at stress concentration points in composite materials - Application to the crack deflection by an interface. In Mathematical Methods and Models in Composites, Computational and Experimental Methods in Structures, V. Mantic Ed., Imperial College Press, London, 401-424.

Li J., Leguillon D., 2016. Finite element implementation of the coupled criterion for numerical simulations of crack initiation and propagation in brittle or quasi-brittle materials, submitted to Engng. Fract. Mech.

Nairn J.A., Hu S., Bark J.S., 1993. A critical evaluation of theories for predicting microcracking in composite laminates. J. mater. Sci. 28, 5099-5111.

Parvizi A., Garrett K.W., Bailey J.E., 1978. Constrained cracking in glass fibre-reinforced epoxy cross-ply laminates. J. Mater. Sci. 13, 195-201.

Sanchez-Palencia E., 1980. Non-homogeneous media and vibration theory. Lecture Notes in Physics 127, Springer-Verlag, Berlin.

Schulze G.W., Erdogan F., 1998. Periodic cracking of elastic coatings. Int. J. Solids Structures 35, 3615-3634.

Shenoy V.B., Schwartzman A.F., Freund L.B., 2001. Crack patterns in thin films. Int. J. Fract. 109, 29-45.

Tripathi D., Jones F.R., 1998. Single fibre fragmentation test for assessing adhesion in fibre reinforced composites. J. mater. Sci. 33, 1-16.

Weibull W., 1951. A statistical distribution function of wide applicability. J. Appl. Mech. 18, 293-297.

Weissgraeber P., Leguillon D., Becker W., 2016. A review of Finite Fracture Mechanics: Crack initiation at singular and non-singular stress-raisers, Arch. Appl. Mech., 86, 375401.

Xia Z.C., Hutchinson J.W., 2000. Crack patterns in thin films. J. Mech. Phys. Solids 48, 1107-1131.

Ye T., Suo Z., Evans A.G., 1992. Thin films cracking and the roles of substrate and interface. Int. J. Solids Structures 29, 2639-2648. 
There are three challenges to overcome: (i) have a criterion to predict crack(s) initiation, (ii) be able to take into account a large number of cracks, (iii) compare to the experiments despite the wide scattering observed in the measurements. 